\title{
Fatores Influenciadores da Garantia e Controle da Qualidade em Pesquisas Econômicas
}

Title: Influencing factors assurance and quality control in economic research

\author{
Márcio de Oliveira Maia \\ Escola Politécnica de Pernambuco \\ Universidade de Pernambuco \\ 50.720-001 - Recife, Brasil \\ mmaialds@gmail.com
}

\author{
Luis Cordeiro de Barros Filho \\ Escola Politécnica de Pernambuco \\ Universidade de Pernambuco \\ 50.720-001 - Recife, Brasil \\ lbarros27@gmail.com
}

\begin{abstract}
Resumo Este artigo aborda a importância da Garantia e o Controle da Qualidade em Pesquisas econômicas, delineando alguns dos principais fatores que tem influência significativa nos resultados esperados. Abordando os processos e as diversas variáveis envolvidas na coleta de dados e procurando entender as relações interpessoais e socioeconômicas inerentes ao meio estudado. O papel do pesquisador, sua comunicação, sua percepção e sua motivação como tendo papel proeminente para assegurar a garantia da qualidade e sua relação com as partes envolvidas. Este trabalho também apresenta conceitos de gestão de qualidade como instrumento de garantia e controle no tratamento e filtragem de dados coletados.
\end{abstract}

Palavras-Chave: Pesquisas Econômicas, Garantia, controle, Qualidade, Comunicação

\begin{abstract}
This article discusses the importance Assurance and Quality Control in economic research, outlining some of the key factors that have significant influence on the expected results. Addressing the processes and the different variables involved in collecting data and trying to understand interpersonal and socio-economic relations inherent in the medium being analyzed. The role of the researcher, his communication, his perception and motivation to have a prominent role to ensure quality assurance and its relationship with the parties involved. This work also presents quality management concepts like security and control instrument in the treatment and filtering of collected data.
\end{abstract}

Keywords: Economic Research, Warranty, Control, Quality, Communication 


\section{Introdução}

A busca por novas informações e a necessidade de tomada de decisões com dados atualizados e confiáveis torna-se um comportamento necessários em qualquer meio. São cada vez maiores os interesses e a necessidade de se fazer pesquisas. A pesquisa torna-se ferramenta para novos conhecimentos. No Brasil, o próprio panorama da conjuntura social e econômica do País tornar-se um campo fértil para estudos diversos. Pesquisar preços, tendências, concorrência, perspectivas, mobilidade, e os impactos sociais e ambientais, principalmente a economia como um todo é parte integrante de um meio em busca de melhores resultados. Estatísticas são traçadas, números são calculados e índices são gerados e delineados buscando entender os diversos comportamentos. As pesquisas aplicadas têm como principal finalidade, diagnosticar, quantificar e avaliar os impactos das políticas econômicas e sociais para apoiar a tomada de decisão pessoal ou corporativa. Há pesquisas que buscam também atender as solicitações de um determinado governo em todos os seus níveis, a instituições nacionais e internacionais, a empresas e a organizações da sociedade civil.

Nessa dinâmica de pesquisas a qualidade das informações passou a ser instrumento de força. Auxiliar as organizações em seu posicionamento perante a sociedade é função estratégica da comunicação. Essa função estratégica, segundo ela, abre canais de comunicação entre a organização e públicos, em busca de confiança mútua, construindo a credibilidade e valorizando a dimensão social da organização [1]. Gerenciar o controle da qualidade é parte fundamental nos processos, na qualidade das informações coletas, geradas e difundidas [2].

"Sistema de gestão da qualidade tem sido um conjunto de recursos e regras básicas, inserida de maneira adequada, com o objetivo de orientar cada processo da empresa para que realize de maneira correta e no tempo devido a suas atividades, sintonia com as outras, estando todas voltadas para o objetivo comum da organização: ser competitiva (ter qualidade com produtividade)", com o propósito de que qualidade é a satisfação dos clientes e produtividade, fazendo mais com cada vez menos recursos [3]. Nisso, a qualidade vai muito além da verificação técnica em busca de defeitos e imperfeições, mas envolve todo o processo produtivo dos produtos ou serviços, é responsabilidade de toda a empresa e a ênfase passa a ser a melhoria para prevenir futuros problemas.

\subsection{Os Institutos de Pesquisas no Brasil}

No Brasil, são vários órgãos, institutos e empresas que trabalham com pesquisas diversas. Quando se fala em pesquisas no Brasil, um dos primeiros nomes lembrado é o Instituto Brasileiro de Geografia e Estatística (IB-
GE). Em sua já razoavelmente longa história, o IBGE elaborou e produziu um conjunto de pesquisas bastante significativo no que diz respeito à oferta de informações sobre as diversas características demográficas e socioeconômicas da população brasileira. Dentre essas pesquisas, o censo demográfico é um eixo de referência para todas as demais.

A Fundação Getúlio Vargas também é outro grande nome quando se trata de pesquisas sobre a economia brasileira. Realiza diversas pesquisas e trabalhos sob encomenda para o setor público, iniciativa privada e organismos internacionais. Além disso, através do Instituto Brasileiro de Economia (IBRE), gera e divulga indicadores e relatórios que contribuem para o direcionamento da economia brasileira. A Fundação Instituto de Pesquisas Econômicas (Fipe) é uma entidade ligada ao Departamento de Economia da Faculdade de Economia, Administração e Contabilidade da Universidade de São Paulo (FEA-USP) que também tem contribuído substancialmente na área de pesquisas no Brasil [4].

\subsection{Pesquisas e Economia}

As Pesquisas econômicas tem abrangência em todo o País, de norte a sul, e a todo momento. A Mídia, os Economistas e a Sociedade têm trabalhado essas informações geradas por Pesquisas, de forma abrangente sempre visando atender suas expectativas, entendimento e tomadas de decisões. Para que possa de fato representar a realidade de um contexto socioeconômico nacional. Porém, a confiabilidade dessa gama de informações cada vez mais presente no dia a dia pode ser questionada sob o ponto de vista das diversas variáveis que formam os seus processos de coleta, processamento e divulgação. Sendo assim, é importante observar que há vários fatores que podem interferir na Garantia e no Controle de Qualidade de uma Pesquisa Econômica.

Nesse sentido, a busca pela qualidade é parte constante nos processos. Programas como Círculos de Controle de Qualidade, Controle Estatístico de Processo, Manutenção Produtiva Total, Melhoria Contínua (Kaizen), Análise dos Efeitos e Tipos de Falhas passaram a ter grande aceitação no mundo ocidental a partir do sucesso percebido com a implantação de técnicas que combinavam o aumento da qualidade e da produtividade [6].

A garantia da qualidade apresenta que em todas as atividades planejadas e sistemáticas que são implementadas dentro do sistema de qualidade procura assegurar que o projeto irá satisfazer os padrões esperados de qualidade. Isso desse acontecer em todo o projeto. Todos os processos envolvidos [7]. A garantia da qualidade é normalmente é implementada pelo Departamento de Garantia da Qualidade ou outro departamento similar, mas lembrando que isso não é uma exigência. A garantia pode ser forne- 
cida à equipe de gerência do projeto e à gerência da organização executora (garantia da qualidade interna), ou pode ser fornecida ao cliente e outros não ativamente envolvidos no trabalho do projeto (garantia da qualidade externa) [8].

\section{Objetivos}

\subsection{Objetivo Geral}

Apresentar os processos que envolvem a coleta de dados para pesquisas econômicas e abordar os aspectos relevantes que contribuem para sua garantia e controle da qualidade.

\subsection{Objetivos Específicos}

- Apresentar conceitos de controle e Garantia de Qualidade

- Descrever os processos que envolvem a coleta de dados para Pesquisas.

- Fornecer variáveis influenciadoras da garantia e controle de qualidade.

\section{Referencial Teórico}

\subsection{Pesquisa}

O homem sempre está em busca de mais informação, de mais conhecimento. Os questionamentos, os problemas, as quantidades, as qualidades sempre foram e serão analisadas. Pesquisar é buscar novos conhecimentos. Pesquisa é a construção de um conhecimento, a construção de novas técnicas, a criação ou exploração de novas realidades. "Essencialmente, pesquisa visa à produção de conhecimento novo e socialmente fidedigno". Um conhecimento que preenche uma lacuna importante no conhecimento disponível em uma determinada área do conhecimento [10].

Ainda não se vê estabelecida uma cultura de realizações de pesquisas como base sistemática para a tomada de decisões. O ciclo de gestão PDCA (do Inglês: Plan, Do, Check, Act ou Action) é à base do processo da rotina e da melhoria contínua, mas sem informações adequadas o ciclo não pode gerar benefícios em busca da excelência, seja no nível micro ou no nível macro. O fato é que sem pesquisa não há informação. E sem informação não há excelência. E sem excelência não há competitividade. É cada vez mais necessário que nossos empresários, gestores públicos do setor em geral entenderem a importância da pesquisa e da informação na tomada de decisões. A partir dessa análise a pesquisa, que com certeza não será mais vista por muitos como um custo; mas passará a ser vista como um instrumento de investimento em busca de excelência e competitividade por meio de provimento de informações que contribuam para decisões mais precisas e conscientes.

\subsubsection{A Evolução da Pesquisa}

A Pesquisa tem sua evolução constante. A cada momento os meios e métodos são aperfeiçoados. Na década de 1960, a pesquisa participativa teve uma crescente de pesquisadores que, principalmente na América Latina, onde se opuseram a uma dominância dos pressupostos da pesquisa positiva e estruturalista. O paradigma convencional foi identificado como parte dos problemas sociais. Paradigmas de pesquisas mostraram-se ineptos para a solução de conflitos e suscitaram uma busca por uma nova relação entre o pesquisador e o pesquisado, uma negociação em torno do objeto da pesquisa, uma outra metodologia de investigação e uma redefinição dos beneficiários da pesquisa [11].

\subsubsection{Conhecimento produzido}

A pesquisa participante considera que o conhecimento é um instrumento de poder e controle, e a pesquisa é um processo oportuno de formação. Todo processo de pesquisa é concebido com um aprendizado educativo e todas as atividades consideradas como ocasião de ampliação do conhecimento da realidade, o conhecimento dará suporte as decisões e garantirá uma unidade ideológica e ética entre o pensamento e a ação. A nova economia é uma economia de conhecimento, onde a tecnologia da informação possibilitou uma economia baseada no conhecimento. Apesar da ascensão da inteligência artificial e de outras tecnologias do conhecimento, este é criado por trabalhadores do conhecimento e por consumidores do conhecimento.

$\mathrm{O}$ intelecto avançado e seu principal facilitador, as tecnologias dos serviços estão remodelando não apenas as indústrias de serviço mas também os padrões globais, argumenta James Brian Quinn, professor da Dartmouth's Tuck School, em Intelligent Emterprise [12].

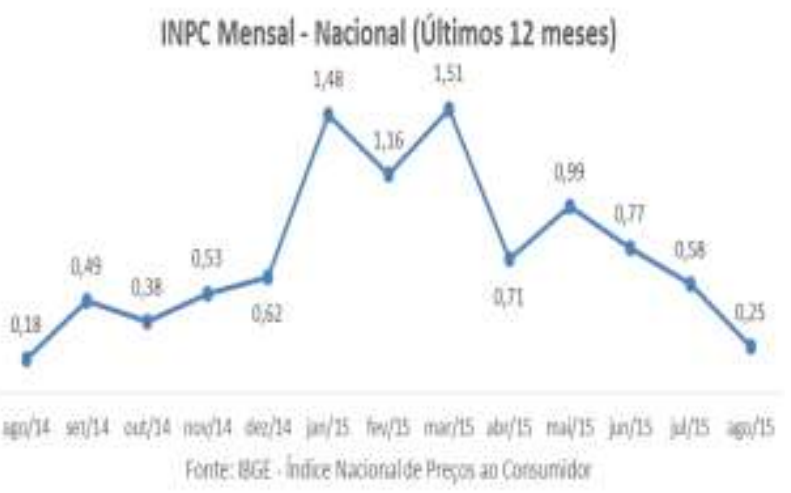




\subsection{Garantia e Controle de Qualidade}

\subsubsection{Garantia da Qualidade}

Segundo a norma NP EN ISO 9001:2008, "a organização deve melhorar continuamente a eficácia do sistema de gestão da qualidade (SGQ) através da utilização da política da qualidade, dos objetivos da qualidade, dos resultados das auditorias, da análise dos dados, das ações corretivas e preventivas e da revisão pela gestão" [13]. Para isso, há várias ferramentas disponíveis para a melhoria dos processos, produtos e serviços. Ferramentas essas que podem servir para acompanhar os processos em suas mais variadas etapas.

O Ciclo PDCA, conhecido também como Ciclo de Shewhart ou Ciclo de Deming, é muito utilizada nas gestões das empresas. Este sistema concebido por Walter A. Shewhart e amplamente divulgado por Willian E. Deming e, assim como a filosofia Kaizen, tem como foco principal a melhoria contínua.

O Fluxograma, conforme Figura 2, tem como finalidade identificar o melhor caminho para um produto ou serviço com o objetivo de identificar as falhas e os desvios. Mostra ainda como cada etapa está relacionada e dependente. Por meio de símbolos, são facilmente reconhecidos para denotar os diferentes tipos de operações em um processo.

O Diagrama Espinha-de-Peixe, ou também chamado de Causa e Efeitos, tem como finalidade explorar e indicar todas as causas possíveis de uma condição ou um problema específico nos processos. Tal Diagrama foi desenvolvido para representar a relação entre o efeito e todas as possibilidades de causa que podem contribuir para esse efeito. Também conhecido como Diagrama de Ishikawa, foi desenvolvido por Kaoru Ishikawa, da Universidade de Tóquio, em 1943 [14].

As folhas de verificação consistem em tabelas ou planilhas usadas para facilitar a coleta e análise de dados. O uso dessas folhas de verificação proporciona uma economia de tempo e organização de informação, eliminando o excesso de números e desenhos repetitivos. São formulários devidamente elaborados para se agir com simplicidade e facilidade, e concisa. $\mathrm{O}$ grande objetivo é permitir que informações sejam de rapidez nas percepções da realidade e uma imediata interpretação da situação, ajudando a diminuir as falhas e a confusão de interpretação.

O Diagrama de Pareto tem como principal finalidade, mostrar a importância de todas as condições existentes em um processo, buscando escolher o ponto de partida para solução do problema e identificar a causa básica, partindo assim para um monitoramento. Este diagrama pode ser usado para identificar o problema mais importante através do uso de diferentes critérios de medição, como frequência ou custo.
O histograma tem como finalidade mostrar a distribuição dos dados através de um gráfico de barras indicando o número de unidades em cada categoria. Um histograma é um gráfico de representação de uma série de dados. O Diagrama de Dispersão mostra o que acontece com uma variável quando a outra muda, para testar possíveis relações de causa e efeito [15].

\subsubsection{Controle da Qualidade}

A ISO 9001 é uma norma de Requisitos de Sistema de Gestão da Qualidade (SGQ) reconhecida internacionalmente, utilizada por organizações que desejam comprovar sua capacidade de fornecer produtos e serviços que atendem às necessidades de seus clientes e das partes interessadas. A norma ISO 9001 é uma referência mundial em SGQ, com mais de um milhão de certificados emitidos em mais de 150 países. Na NBR ISO 9000-2005 "controle da qualidade é parte da gestão da qualidade, focada no atendimento dos requisitos da qualidade". Dessa maneira, tem como papel principal fiscalizar, controlar e tem como objetivo avaliar e garantir se a especificação esta ou não sendo atendida. Já "garantia da qualidade faz parte da gestão da qualidade focada em prover confiança de que os requisitos da qualidade serão atendidos", estando diretamente relacionada ao atendimento dos requisitos de qualidade no processo como um todo (produção, pessoas, equipamentos, demais departamentos) [16].

Segundo a ISSO 9000-2000, de conceitos, controle de qualidade é "a atividade e técnica operacional que é utilizada para satisfazer os requisitos de qualidade". O controle de qualidade pode ser feito de diversas maneiras. Por inspeções, revisões e testes, usados através do ciclo de desenvolvimento para garantir que cada trabalho produzido está de acordo com sua especificação/requerimento. Portanto, o controle de qualidade é parte do processo de desenvolvimento e, como é um processo de feedback, ele é essencial para minimizar os defeitos produzidos. A norma ISO 9001 é aplicável a qualquer organização - independentemente do tamanho, setor em que opera, tipo de produto ou serviço e localização geográfica. Um dos principais pontos fortes da norma ISO 9001 é a sua adequação a todos os tipos de organizações.

Hierarquias de qualidade

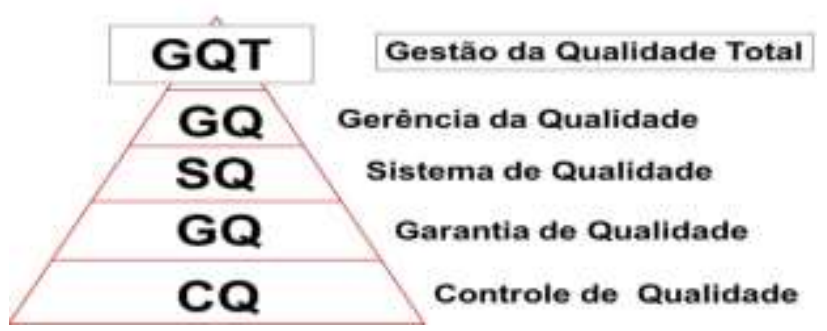




\section{Aplicações e Resultados}

\subsection{Fatores Influenciadores da Garantia da Qualidade}

\subsubsection{As Interrogações iniciais}

Toda pesquisa tem um objetivo: levar a tomar conhecimento da situação de existência ou não de um problema, formulando interrogações iniciais e dar apoio a tomada de Decisão com precisão contribuindo-se para agregar valor e maximar resultados das ações a posteriori.

Nossas experiências são essencialmente uma mistura de conhecimento e de valores, dos quais se dispõe, em maior ou menos quantidade, como mais ou menos variedade de amplitude e de domínio. Esses conhecimentos e valores são recebidos prontos e conservados, ou aprendese ou transforma-se, adaptando-os por vezes, ou seja desenvolvendo-os.[15]

\subsubsection{O Problema da Pesquisa}

O que mobiliza a mente humana são os problemas. A busca de um maior entendimento de questões postas pelo real, ou ainda a busca de soluções para problemas nele existente, tendo em vista a sua modificação para melhor.

A pesquisa parte de um problema e se escreve em uma problemática. A fase de estabelecimento e de clarificação da problemática e do próprio problema é considerada muitas vezes como a fase crucial da pesquisa. Ela serve para definir e guiar as operações posteriores.[17] O controle é parte das pesquisas. O objetivo é documentar, registrar e comprovar. Quanto maior a formalização para estes processos, maior é o controle e a qualidade.[18]

\subsubsection{Pesquisas Ativas}

A pesquisa-ação e pesquisa de intervenção; e a pesquisa participativa. Estas abrigam um amplo aspecto de orientação epistemológicas e prática de pesquisa que derivam de diferentes concepções, pressupostos, origens e usos distintos na América, Europa, Austrália e Ásia, tendo como interesse comum a classificação dos fatos com a finalidade de orientar a ação em uma situação concreta, mantendo alguns elementos comuns. Criticar o modelo convencional, manifesto de aprofundar conhecimento, escolha e analise de informações e favorecer o desenvolvimento. Tais pesquisas visam auxiliar a promoção de algum tipo de mudança desejada.[5]

\subsubsection{Pesquisas Participativas}

Pesquisas participativas surgem como uma forma alternativa, desgarrando-se das formas manipulativas de pesquisa-ação. Ela tem como pressuposto a democratização da produção do conhecimento e da sociedade e o desenvolvimento da justiça social. Não é um mero con- junto de métodos, meios e técnicas, mas se fundamenta em uma ética e em uma concepção alternativa de produção popular do conhecimento. Trata-se de um modelo e de um meio de mudança efetiva na qual os sujeitos implicados devem elaborar e trabalhar uma estratégia e mudança social.[6]

\subsubsection{Comunicação e Pesquisa}

Ao registrar a busca do conhecimento objetivo não se pode, entretanto, esquecer que a ciência é um fenômeno social e histórico, sujeito a condicionamentos e influências. O que significa: é também parcial e sujeita a erros. Não ultrapassa, por vezes, o senso comum, e é com frequência permeada pela ideologia (ou pelo viés dos interesses, da preservação ou conquista de posições de poder).

Facilitar a comunicação passa a ser tarefa fundamental nas relações. No próprio sentido da palavra comunicação origina-se do latim, que significa tornar comum ou compartilhar. Sendo assim, a comunicação é uma informação transmitida a alguém, compartilhada.[19]

Trata-se ai de um conhecimento vivo, intuitivo, espontâneo - e que apresenta uma grande riqueza em função de seu enraizamento no terreno da experiência e sua sintonia com o viver cotidiano, com as indagações, problemas e desejos que povoam a vida do dia-a-dia.[20]

\subsubsection{Os Prazos}

Os prazos de pesquisas são importantíssimos para a qualidade das informações. Os prazos são diversos. Muitos índices têm periodicidade diária. Índices como o Índice de Preço ao Consumidor (IPC), da Fundação Getulio Vargas, tem periodicidade diária. As donas de casas, autônomas que pesquisam feiras livre e supermercados, logo cedo estão nas ruas coletando preços.

Há também periodicidades diversas. Semanais, descendais, mensais e anuais. Tudo de acordo com a necessidade dos índices ou solicitações públicas e privadas.

A busca para se atingir os prazos estabelecidos sofre interferências de inúmeros fatores que vão desde a mobilidade nas grandes cidades até a dificuldade de encontrar produtos com descrição única ou exclusiva. Os produtos que são fabricados por um único fabricante podem condicionar a pesquisa a uma espera bem maior que o comum e, coloca em risco os prazos estabelecidos e objetivos das informações.

Informações coletadas fora dos prazos podem influenciar significativamente nos resultados das pesquisas, mesmo que existam meios que minimizem as ausências destes dados.

A regularidade e a constância da coleta de dados das pesquisas também são bastante comprometedoras para os 
prazos. A condição rotineira de se coletar dados numa determinada organização, empresa ou com uma pessoa, pode gerar um certo desconforto e desinteresse na continuidade, podendo até correr o risco de se coletar informações incorretas devido a desmotivação por parte do pesquisado. Tal pesquisado começa a ver as pesquisas com insignificância, descaso e incompreensão, interferindo involuntariamente ou proposital nos dados fornecidos. Para os casos de pesquisas de preços, um risco eminente oriundo do desestímulo por se pesquisar com muita frequência, é que o pesquisado acaba solicitando ao pesquisador que repita os preços anteriores. Essa postura, se não bem averiguada e percebida pode causar sérias interferências nos resultados, principalmente em pesquisas com grande quantidade de informações a serem coletadas em um único informante.[21]

\subsubsection{A quantidade de informações}

A quantidade de informações coletadas para cada pesquisa, normalmente é outro fator bastante influenciador dos resultados. Questionários extensos, perguntas longas e, grandes quantidades de produtos e preços, tem gerado um desafio para as pesquisas e pesquisadores, promovendo um certo descontentamento e desinteresse pelas partes envolvidas no processo de coleta.

Se por um lado a grande quantidade de informações otimiza a questão tempo versos dados coletados, por outro lado corre-se o risco eminente de parte das informações coletadas não representar o contexto esperado, pois muitos dos pesquisados não querem dispender tempo demasiado para tais pesquisas em virtude de muitos destes entrevistados encontram-se em plenas atividades profissionais. Sendo assim, podem passar informações incorretas e até informações inexistentes. Um exemplo disso é passar o preço de um medicamento em que o estoque está zerado.

Muitas pesquisas de preços são realizadas com vendedores dos estabelecimentos comerciais. Estes veem nas pesquisas longas, com grandes quantidades de informações a serem coletadas, como um momento em que estão perdendo oportunidades de efetuarem suas vendas e aumentar seus rendimentos.

Para buscar não impactar tanto nesse tipo de situação, cabe ao pesquisador ter uma boa e amigável relação de confiança e, sempre procurar agendar o dia de sua visita, atentando assim para a melhor conveniência do entrevistado.[22]

Supervisores, gerentes e diretores de empresas e estabelecimento comercial por vezes também não querem que seus funcionários se envolvam nas pesquisas. $\mathrm{O}$ tempo despendido e até a confidencialidade das informações passadas preocupa os gestores e torna-se mais um empecilho para o bom andamento das pesquisas rotineiras e longas. Para estes casos, também se torna necessário o bom entendimento e a relação amigável que deverá ser construída entre todas as partes envolvidas.

Muitas pesquisas apresentam questionários longos com até mais de trinta perguntas, como são os casos das pesquisas de sondagens industriais, expectativas do consumidor e demais sondagens conjunturais. Para as pesquisas de preços, nos supermercados, farmácias e feiras livres, esse número de informações a serem coletadas chegam a mais cem preços.

Para o caso das pesquisas em supermercados, o próprio pesquisador vai até os produtos sem quase nenhum suporte e auxilio de funcionários, salvaguardando em momentos específicos de dúvidas ou não encontrar o produto solicitados na pesquisa.

Mesmo não necessitando de suporte para coletar as informações, ainda assim o ambiente de supermercado por vezes é dinâmico e pode interferir no tempo hábil para coletar.[23]

\subsubsection{Pesquisas e Sazonalidade}

Não é somente a questão dos preços que ficam mais caros dependendo de um determinado período do ano. Sazonalidade também é outro fator impactante para a coleta de dados dentro dos prazos estabelecidos. Um grande exemplo disso é coletar valores de mensalidade escolares justamente no período de início de ano letivo, onde normalmente todas as atenções da administração das escolas estão voltadas para as matriculas e assuntos relacionados ao início do ano curricular e retorno de férias. Muitos se esquivam em passar informações que não estejam voltadas diretamente e exclusivamente a matricula de alunos.

Para minimizar problemas como este, cabe ao pesquisador munido de um bom treinamento e um senso de percepção atento agir com o informante com clareza e cordialidade, visando sempre manter uma relação de confiabilidade e cordialidade.[24]

\subsubsection{Autorização para pesquisa}

Muitos dos itens solicitados nas pesquisas abrangem inúmeros seguimentos que vão desde um supermercado, feira livre e farmácia até a uma multinacional como a Petrobras e empresas estrangeiras. Sendo assim, outra dificuldade impactante no ato de coleta de informações, principalmente em empresas de grande porte, são suas políticas organizacionais de confidencialidade e privacidade. Para algumas destas empresas é necessário obter uma autorização prévia da diretoria da empresa para assim ter acesso às informações. Esse processo para autorizar a coleta de dados pode durar até meses para se concluir. Isso é muito comum, sobretudo para produtos e itens de exclusividade de monopólio industrial. Parece 
parte inerente de uma cultura organizacional. O comportamento humano nas organizações tem sido motivo de muitos estudos ao longo do tempo. Tornou-se um assunto abrangente e voltado sempre a entender as diversas performances das pessoas e os ambientes em que estão inseridos, sobretudo diante do crescimento e novos desafios das empresas em um panorama cada vez mais crescente e globalizado. Existem diversos trabalhos e pesquisas que abordam cuidadosamente, analisam e fundamentam os comportamentos organizacionais.[25]

A cultura está vinculada à existência de um grupo social, que compartilha de uma mesma língua e espaço durante certo período de tempo, criando formas de perceber, pensar e decidir que tenham dado certo a ponto de serem institucionalizadas em procedimentos padrões, costumes, scripts e pressupostos não declarados que guiam os comportamentos das pessoas que dele fazem parte.[26]

\subsubsection{Pesquisas e mobilidade}

As pesquisas presenciais de cunho econômico ainda são muito comuns e necessárias. E, movimentar-se nas grandes regiões metropolitanas no Brasil é uma tarefa cada dia mais complicada e, tais problemas de mobilidade tem interferência direta e indiretas na coleta de dados. Os problemas são comuns desde para quem se utiliza de veículo próprio até para quem usa o transporte público. Ficar preso em um engarrafamento ou procurar vaga de estacionamento num momento em que uma determinada pesquisa tem prazo estabelecido para ser coletado pode ser o maior agravante para um pesquisador atingir seus objetivos.

As pesquisas diárias sofrem grande influência desse problema, cabendo ao pesquisador grandes esforços e planejamento extra de roteiro. A Norma Brasileira 9050 da Associação Brasileira de Normas Técnicas[2] visa promover a acessibilidade no ambiente construído e proporcionar condições de mobilidade, com autonomia e segurança, eliminando as barreiras arquitetônicas e urbanísticas nas cidades, nos edifícios, nos meios de transporte e de comunicação. Sendo assim, ainda se encontra muitas dificuldades de locomoção nos grandes centros urbanos. $\mathrm{O}$ custo com transporte e mobilidade extra para se chegar a um determinado local de pesquisa tem levado muitos pesquisadores a pensar mais ponderadamente quando aceitam o encargo de ser pesquisador.

\subsubsection{A percepção do pesquisador}

O profissional pesquisador assume papel importante de animar o intercambio de informações. Ele atua no sentido educativo, organizando a participação, as condições de discussão e de analise. Ele precisa garantir a interlocução dos diferentes seguimentos sociais e a comunicação permanente de todos os participantes. Sendo assim, o pesquisador necessidade de atributos e grande capacidade de percepção e comunicação. Deve ser treinado e preparado para perceber e analisar as diversas situações enfrentadas. Assim, a percepção ambiental está ligada à captação e ao tratamento da informação externa considerada útil para a organização. Contudo, na seleção e percepção ambiental não são as organizações em si que selecionam e percebem seus ambientes, mas sim as pessoas que administram as organizações.[25]

Na Figura 1, mostra a figura onde é apresentado os dados do índice nacional de de preço ao consumidor, norteando a economia nacional. São esses e demais dados gerados por pesquias que representam informações onde empresas e sociedade fazem uso e buscam atender sua diversas necessidades sociais. As pessoas precisam reconhecer objetos para interagirem significativamente com seu ambiente, dentro desse processo tem-se a percepção social, a qual envolve uma sequência de processamento de informações (daí o rótulo "processamento de informações sociais"). Seguindo um modelo básico de processamento de informações, é possível observar três dos estágios neste modelo: atenção seletiva/compreensão; codificação e simplificação; e armazenamento e retenção descrevem como informações sociais específicas são observadas e armazenadas na memória. O quarto e último estágio, de recuperação e resposta, envolve transformar representações mentais em julgamentos e decisões do mundo real.[6]

\subsubsection{Treinamento e recrutamento dos pesquisado-} res

Os novos pesquisadores são recrutados assim que a necessidade demandar. Tais necessidades são oriundas de novas pesquisas ou mesmo para compor o quadro atual de pesquisadores. Para os institutos federias a ingressão se dá por meio de concursos públicos. Em outros Institutos ou empresas de pesquisas, muitos novos funcionários são inseridos por meio de estagiários. Os pesquisadores e demais funcionários recebem treinamentos periodicamente nas sedes da empresa. Todas as mudanças e novos procedimentos são passados presencialmente ou por meio de vídeo conferencia. Para as empresas que não tem a sede na cidade referência, os técnicos, analistas e economistas viajam para o devido fim.

Manter os padrões e metodologias estabelecidas é papel fundamental para a qualidade. A formalização serve para reduzir a variabilidade da informação. Ele impõe a rigidez e obediência a liberdade pessoal, a fim de assegurar que as coisas sejam feitas exatamente de acordo com o previsto. Porém, um ponto fundamental nos processos de trabalho e treinamento de pessoal, é entender que o instrumento essencial é a Comunicação. Conectividade e interação estão substituindo a formalidade nas relações entre as pessoas.[27] 
As ameaças às organizações, vindas dos clientes, da concorrência e em decorrência das mudanças no contexto socioeconômico requerem habilidades humanas em alto grau de refinamento. A compreensão do comportamento individual e dos grupos em situação de trabalho constitui o campo de estudo do Comportamento Organizacional e é capaz de identificar situações de liderança, melhoria e aprendizagem.[25]

\subsubsection{Padronização dos processos de coletas}

Todos os processos de coleta de dados são devidamente padronizados. Desde uma simples planilha e questionários, até os mais complexos sistemas de dados. As abordagens realizadas por telefone, presencial e por diversos meios seguem um script de procedimento, normas e ética. Os pesquisadores são identificados por meios de uniformes ou mesmo usando um crachá. Os informantes são catalogados, sobretudo aqueles que participam de pesquisas rotineiras e sequencial, estes são cadastrados seguindo o padrão de coleta de dados que inclui desde o CNPJ, endereço, e os nomes dos principais contatos. As pessoas, empresas e órgãos que participam das pesquisas precisam estar cientes de que estão participando de uma pesquisa, que isso segue como parte da boa relação entre pesquisador e pesquisado e preparação do profissional frente a suas atribuições. $\mathrm{O}$ treinamento nas organizações é voltado principalmente para complementar a competência de conhecimento em "o que fazer" e em "como fazer" [2]. Ressalte-se que não se pode esquecer que o aprendizado ocorre no dia-a-dia ao longo do tempo e que existem mecanismos onde a organização que aprende pode influir nos resultados finais.[29] Em alguns casos será necessário uma autorização formal para se realizar a pesquisa, seguindo um modelo previamente estabelecido.

\subsubsection{Padronização dos processos de divulgação}

Algumas pesquisas ganharam muita expressividade no meio social e é tratada com muita importância para os meios de comunicação. Os economistas e a impressa de modo geral necessitam de pesquisas que tenham notoriedade e confiabilidade. As pesquisas são divulgadas amplamente e, devido demanda e os prazos, são estabelecidos meios padronizados para a divulgação destas. Meios, datas e procedimentos devidamente agendados e monitorados. É reservado um setor especifico para a área de divulgação, que se integra em muitos casos com a área comercial, mantendo assim a padronização deste processo tudo isso visando a qualidade das informações geradas. Sendo assim, entende-se que o mais importante é o que o usuário percebe em relação à qualidade.[30]

\subsubsection{Confidencialidade nas informações}

Todos dados coletados, gerados e divulgados são na integra devidamente envolvidos num caráter de confidencialidade. Tal procedimento é deixado bem evidente logo na parte inicial do processo de coleta, onde quem está sendo pesquisado também estará sendo informado que suas informações serão mantidas em sigilo. Em alguns casos termos de responsabilidades são assinados visando sempre a segurança das informações e das partes envolvidas. Segundo a ISO 9001 versão 2008, os registros são um tipo especial de documento e precisavam ser controlados.

Os registros são estabelecidos e mantidos para proverem evidências da conformidade com requisitos e da operação eficaz do Sistema de Gestão da Qualidade. Todos os registros devem ser mantidos legíveis, prontamente identificáveis e recuperáveis. Um procedimento documentado é estabelecido para definir os controles necessários para identificação, armazenamento, proteção, recuperação, tempo de retenção e descarte dos registros da qualidade.

\subsubsection{Segurança dos Sistemas de dados}

Os sistemas informatizados que regem os grandes bancos de dados das Instituições de pesquisas são mantidos sob um rígido controle de segurança. $\mathrm{O}$ acesso e manuseio destes equipamentos somente são possíveis mediante a um padronizado e especializado sistema de privacidade. Isso vai desde um simples computador de mesa, notebook até aos grandes processadores dos centros gerenciais. Em sua grande maioria serão necessários mais de um tipo de senha e login para adentrar estes sistemas. O foco é manter protegido aquilo que é de mais importante e fruto de um empenho considerável, buscando assim fundamentar a questão qualidade na segurança frente a quem busca e necessita dessas informações. Uma gestão da qualidade eficiente é responsável por gerar níveis de satisfação que garantam que os usuários fiquem fidelizados.[31]

\subsubsection{Os meios de coleta de dados}

Os meios de coleta de informações para pesquisas também são processos bem definidos que se diferenciam um do outro não somente quanto a metodologia e ferramentas usadas mas também pelo grau de complexidade, de comunicação, percepção e motivação, onde necessariamente cabe estudos e analises dentro da gestão da qualidade dos processos.

Os princípios da gestão da qualidade relaciona-se ao "enfoque por processos". De acordo com esse princípio, um resultado desejado é alcançado mais eficientemente quando as atividades e os recursos relacionados são gerenciados como um processo. Segundo a ISO 9000, processo é o "conjunto de atividades inter-relacionadas ou interativas que transformam insumos (entradas) em produtos (saídas)".[2]

\subsubsection{Pesquisas por telefone}


É cada vez mais comum e necessário a interação por telefone principalmente para pesquisas. A viabilidade do sistema facilita em todos aspectos. Grande parte das pesquisas na atualidade são realizadas por telefone. Pesquisas de economia também é realizada por telefone, muito comum em pesquisa de preços e de opinião.

Esse tipo de pesquisa é prático e também reduz custos diversos e problemas de mobilidade nos grandes centros.

"A entrevista telefônica está se tornando gradualmente o método dominante para obtenção de informações de grandes amostras, à medida que os custos e problemas de não respostas de entrevistas pessoais tornam-se mais complicados. Ao mesmo tempo, muitas das limitações conhecidas das entrevistas telefônicas tem se revelado de pouca significância para uma grande parte dos problemas de marketing."'[32]

Com o crescente acesso à telefonia por parte da população das mais variadas camadas sociais, a pesquisa por telefone vem sendo cada vez mais utilizada em pesquisas quantitativas. Tem se observado uma crescente insatisfação das pessoas por serem muitas vezes incomodadas com excesso desse tipo de prospecção de informação. Excesso de pesquisas, de perguntas e até pesquisas ilegais. Para as pesquisas de preços e de sondagens conjunturais, o primeiro passo é fidelizar um contato. Um representante da empresa que possa passar as informações regularmente. Ligar para uma empresa já sabendo com quem vai se falar é estrategicamente mais proveitoso e confiável. Nestes casos, busca-se por meio de uma visita presencial fortalecer a relação pesquisa, pesquisado e pesquisador visando estreitar o entendimento e o comprometimento das partes envolvidas e assim, mantendo nas pesquisas por telefone a relação previamente de comprometimento e fidelização de um processo. A exposição e o uso permanente dos meios de comunicação fazem deles práticas e objetos familiares e amplamente conhecidos pelos membros da sociedade. Fala-se dele, de seus conteúdos, do desempenho dos personagens que os habitam; domina-se, em certa medida, seu funcionamento e para eles são dirigidas as críticas.[33]

Para atenuar os impactos causados pela assiduidade e constância dessas pesquisas por telefone torna-se necessário conhecer também a cultura organizacional de cada empresa envolvida na amostragem, para assim poder adaptar ao informante a melhor forma de coleta dos dados, se por telefone, e-mail ou mesmo presencial. As ligações não completadas por estarem ocupadas, ou porque o aparelho encontrar-se com defeito, gerarão novas tentativas. Quantas tentativas forem necessárias. E, se finalmente não se consegue a comunicação por telefone, será buscado outro meio. Pesquisar na internet se há outro número de telefone. Se o problema persistir, ainda restam as iniciativas de ligar para um estabelecimento vizinho para obter informações. E, em outra tentativa, se fará uma visita presencial.

\subsubsection{Pesquisas por E-mails}

As interações por e-mails para pesquisas é cada vez mais comum no contexto de pesquisas econômicas. Traz algumas das problemáticas encontradas em outras formas de coleta, porém representa um meio confiável e padronizado. Já existem empresas que disponibilizam funcionários exclusivos para atender também as demandas de pesquisas diversas.

A pesquisa por e-mail tem certas particularidades devido ao padrão do questionário ou planilha, e do direcionamento especifico para o setor necessário. Diferente da pesquisa por telefone onde o pesquisador geralmente coleta a informação no ato da ligação, a pesquisa por email o contato saberá que tem uma data limite para enviar as informações. A maneira como se descreve as informações e questionamentos no corpo de um e-mail pode ser extremamente influenciador na relação pesquisa e pesquisador. O e-mail também se torna um documento de confiança e comprovação.

\subsubsection{Pesquisas por Sites}

Tem se mostrado um dos meios mais práticos de se coletar preços para pesquisas os sites na internet. Muitos estabelecimentos comerciais já disponibilizam seus portfolios, tabelas de preços e produtos nas suas páginas da internet. Apesar dos pontos positivos, ainda existe a insegurança. Alguns sites não atualizam suas informações imediatamente. Órgãos públicos, sindicatos e até empresas comerciais não atualizam suas informações com a precisão necessária para a pesquisa com data marcada. Para esse tipo de pesquisa também torna-se necessário que haja um contato por telefone para eventuais esclarecimentos.

\subsubsection{Pesquisas presenciais}

A pesquisa presencial já foi o meio mais comum de coleta de dados. Hoje, em virtude das facilidades apresentadas por modernos meios de comunicação some-se a isto as dificuldades de mobilidade nos grandes centros urbanos, é cada vez menos comum esse tipo de abordagem para se executar pesquisas de preço. Redução de despesa é um fator também contribuinte. As pesquisas in loco segue um cronograma sempre direcionado a pesquisas com um grau de dificuldade diferenciado. Normalmente para informantes que não querem passar informações por telefone ou por outro meio de pesquisa. Normalmente segue conforme fluxograma na Figura 3: 


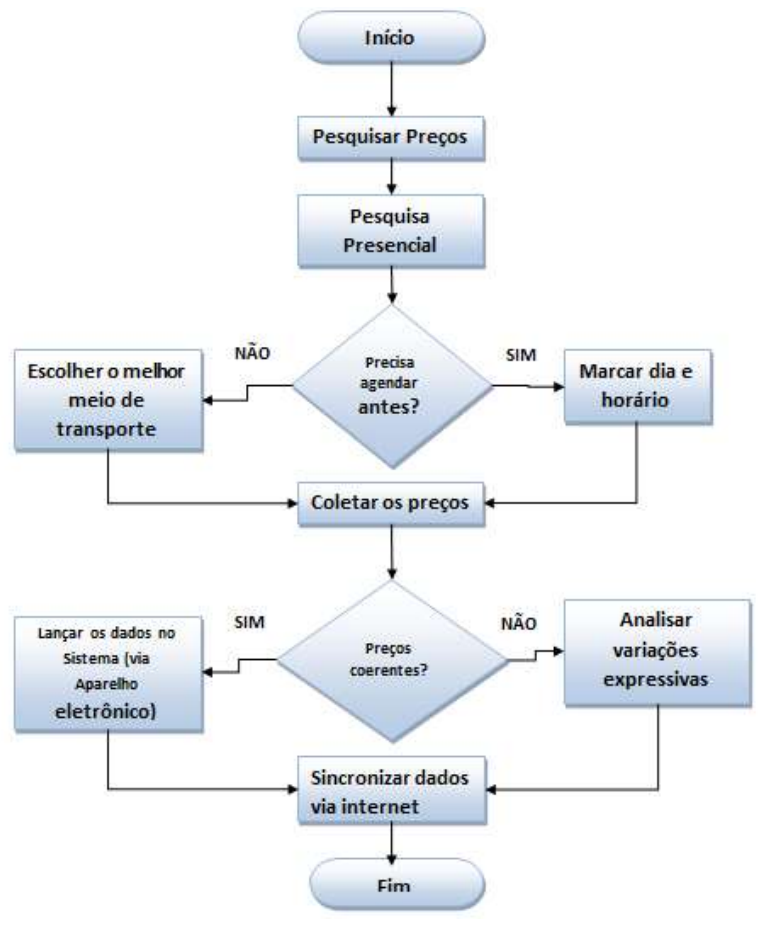

Figura 3: Fluxograma do processo de pesquisa presencial.

As pesquisas presenciais têm sua grande importância e pode apresentar características únicas e determinante para um estudo conforme esse material. As análises dos processos inerentes a pesquisas in loco vão desde a abordagem, a comunicação, a percepção até ao perfil profissional do pesquisador. A Figura 4 mostra um pesquisador em uma pesquisa presencial fazendo uso de um equipamento de coleta de dados.[34]

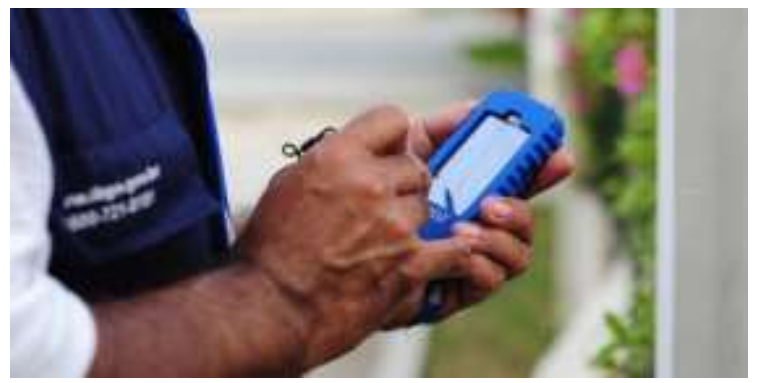

Figura 4: O pesquisador coletando informações com um dispositivo eletrônico.

\subsubsection{As Donas de Casa e as Pesquisas}

Nada melhor para entender de preços e economia no lar do que as donas de casa. Elas estão de frente quanto o assunto é variação de preços e descrição de produtos., Elas são provavelmente as primeiras a perceberam os reajustes e demais influências nas variações de preços. Sendo assim, percepção é fundamental no ato de uma pesquisa. Percepção é o processo pelo qual os indivíduos selecionam, organizam, armazenam e recuperam informações. Decisão é o processo pelo qual as informações percebidas são utilizadas para avaliar e escolher entre vários cursos de ação. As pesquisas têm demonstrado que o modo como as organizações tomam decisões exerce um grande impacto no seu desempenho financeiro e na sua capacidade de sobrevivência, e isso é particularmente verdadeiro em ambientes complexos e dinâmicos.[25]

Recrutar donas de casa para conferir os preços praticados pelos estabelecimentos comerciais que atendem o consumidor final é uma tradição do Instituto Brasileiro de Economia da Fundação Getúlio Vargas. Algumas destas donas de casa já somam mais de 30 anos na função. Com smartphones nas mãos, essas donas de casa seguem um roteiro de pesquisa de preços em Supermercados, feiras livre e farmácias. Tudo previamente definido. Já são conhecidas nos estabelecimentos que frequentam para realizar as pesquisas. Para candidatar-se, é preciso preencher uma ficha nos escritórios regionais de pesquisa da Fundação. Após uma pré-seleção, chama-se a candidata para uma entrevista, a fim de avaliar se ela tem as características necessárias para a execução do trabalho. A remuneração do trabalho é definida pela faixa de produção.[35]

\subsubsection{Auditorias de qualidade}

Parte necessária para um acompanhamento da qualidade, a auditoria de qualidade vem a ser uma revisão estruturada das outras atividades de gerência da qualidade. A principal finalidade da auditoria da qualidade é identificar as lições aprendidas que melhorem o desempenho deste projeto ou de outros projetos da organização. Para as empresas de pesquisas, as auditorias são instrumentos também de exigências dos clientes, tendo em vista que muitas pesquisas atendem a órgãos e instituições públicas e privadas. A auditoria de qualidade pode ser implementada em qualquer período, podendo ser conduzida tanto por auditores internos adequadamente treinados, quanto por empresas contratadas com registro de sistemas de qualidade. Nessa nova abordagem, o controle de qualidade deixa de ser uma função de responsabilidade específica de gerentes de departamentos de qualidade para ser exercida por todos os empregados em todas as fases do processo produtivo. Daí a origem de sua nova denominação - Controle de Qualidade Total.[36]

A melhoria da qualidade inclui a tomada de ações para aumentar a efetividade e a eficiência do projeto fornecendo benefícios adicionais para as partes envolvidas do projeto. Na maioria dos casos, a implementação de melhorias na qualidade exigirá preparação de requisitos de mudanças ou tomada de ações corretivas e serão gerenciadas de acordo como os procedimentos do controle integrado das mudanças. Na Figura 5, exemplo de um processo de auditoria em pesquisas realizadas por telefone, em uma empresa do ramo de pesquisas econômicas no Estado de Pernambuco. 


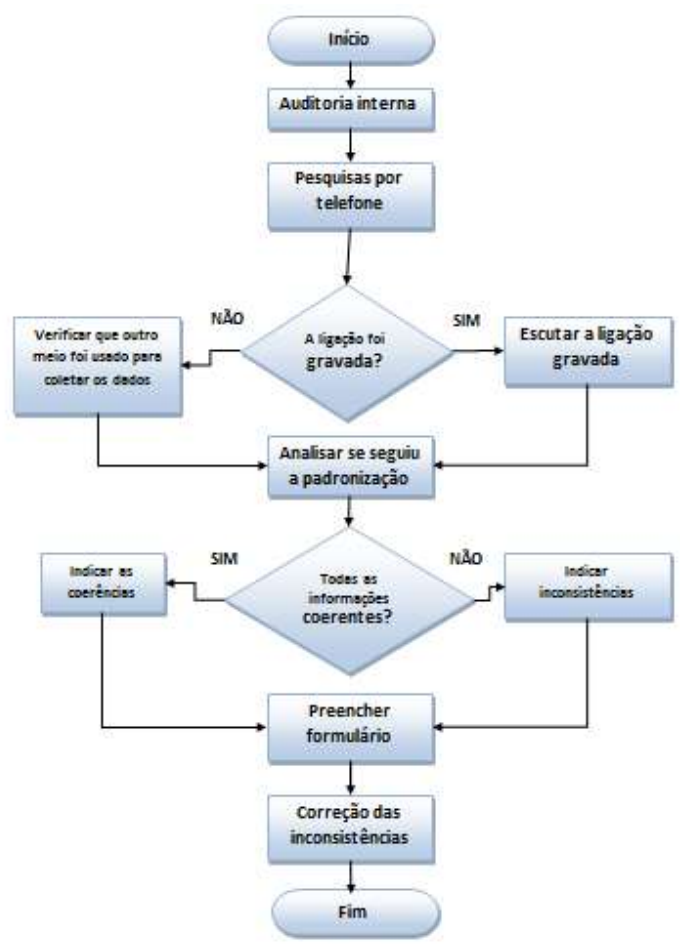

Figura 5: Fluxograma do processo padronizado de auditoria interna.

\subsection{Fatores influenciadores do Controle da Qualidade}

\subsubsection{Disseminação dos Resultados}

Parte relevante da pesquisa participativa, a disseminação dos resultados precisa ser organizada de forma que a difusão das informações e das ações propostas sejam compartilhadas, para que a maior parte da comunidade partilhe dessas informações e ingresse no processo, engajando-se nas ações ou apoiando efetivamente as iniciativas.

Para Gale (1996) a qualidade percebida é o que os usuários pensam a respeito dos produtos ou serviços, comparando com os da concorrência, enquanto o valor percebido é a qualidade que o mercado percebe em relação ao produto ou serviço. Sem esse cuidado, a pesquisa pode perder seus objetivos e inviabilizar os resultados esperados.[37]

\subsubsection{Pesquisas econômicas}

A Economia é uma ciência social, não está livre de críticas dessa natureza. Se as criticas feitas aos economistas são fundamentadas não cabe discutir aqui. Basta dizer que a Economia, como outras ciência sociais, apresenta mais dificuldades do que as ciências naturais para fornecer explicações satisfatórias acerca de seus fenômenos. É importante considerar que com a introdução dos procedimentos estatísticos na investigação da economia, essa ciência passou a gozar de maior grau de precisão.[34]

\subsubsection{Pesquisas de Preços}

Os preços norteiam a economia brasileira como sendo um dos principais fatores de acompanhamento inflacionário. O momento é de pesquisar preços. Com a economia nacional instável as famílias brasileiras não podem deixar de pesquisar preços nos supermercados, farmácias e quitandas. O povo brasileiro já tem feito isso com muita sutileza e, o que se tem aprendido é, para manter o padrão de consumo da família, tem se mudado costumes, feito trocas e comprando menos os produtos que mais encarecem nas gôndolas. Sendo assim o carrinho de supermercado sai mais leve, mas a fatia do salário consumida com os alimentos cresce a cada mês. É a inflação amedrontando as famílias. Tendo essa percepção cada vez mais aguçada, os preços tornam-se uma ferramenta indispensável em termos de acompanhamento da carestia. A inflação no Brasil é dividida em preços livres e preços administrados. Os Livres são aqueles regulados pelo próprio mercado, como os ligados aos produtos de alimentação. Estes têm um peso próximo de $75 \%$ no PIB no País. Já os preços administrados, como gasolina, energia, água e esgoto, transporte público, etc., estes tem peso próximo de $25 \%$. Nota-se que os preços administrados tem tido grande peso na inflação. Por isso a grande necessidade de ser acompanhado, pesquisado e analisado sistemática e integralmente sempre visando nortear decisões, comportamentos e perspectivas.[39]

Alguns institutos de pesquisas tem um foco bem direcionado as pesquisas de preços. O Instituto Brasileiro de Economia da Fundação Getúlio Vargas, a FIPE e o Dieese são algumas dessas organizações brasileiras que tem referencial e credibilidade significativa quando se trata de preços diversos coletados. Preços de alimentos, preços de medicamentos, aluguel, carros. Essas pesquisas são realizadas presencialmente, por telefone, por e-mail e pela internet. A periodicidade da coleta varia chegando a ser semanalmente, quinzenalmente e mensalmente. Normalmente são produtos, itens e serviços já previamente selecionados de acordo com a importância e peso nos índices.

\subsubsection{Os itens pesquisados}

O tipo de produto e a questão analisada numa pesquisa pode ser um do problema enfrentado pelos pesquisadores em suas rotinas diárias de pesquisas. Muitas perguntas de difícil entendimento, dúbia ou descrições de produtos incoerentes, com códigos e referencias, e termo técnico tem trazido muitas divergências nos resultados. Excesso de informações ou mesmo, a ausência de informações especificas e claras promovem dificuldade e confusão no ato da coleta de preço. Em exemplo evidente disso é pesquisar um produto onde o pesquisador sequer sabe sua finalidade. Não saber o objetivo e a finalidade pode interferir em algum momento de argumentação para esclarecer eventual dúvida existente e, não confundir com 
outro produto similar. Fabricantes também alteram suas embalagens, gramaturas e códigos com regularidade. Sendo assim, além da dificuldade de compreensão essa problemática tem causado muito desinteresse e equívocos em pesquisas, sobretudo econômica. Muitos informantes não estão dispostos a fornecer dados minuciosos e dispender muito tempo para responder pesquisas do gênero.

\subsubsection{Descrição do produto}

Quanto a compreensão da descrição de um produto, um exemplo clássico observado na Região Metropolitana do Recife está nas pesquisas realizadas em armazéns de material de construção para a coleta do preço de cimento. Tendo em vista que, uma grande maioria de vendedores não entende a diferença ou mesmo não sabem a descrição correta do produto, pois, para cimento portland existem várias classificações para diferentes tipos de aplicações. No Brasil são mais de 10 tipos de Cimento, porém, muitos desconhecem e acabam fornecendo preços incorretos, pois o preço de um Cimento Portland CP II é diferente do CP IV.

Há também a descrição do produto que muda dependendo da região do país. Alguns apresentam nomes completamente diferentes ou com acréscimo de informação. Na Região Metropolitana do Recife em armazéns de material de construção civil, se compra brita pelo tamanho. A brita dezenove é a brita de dezenove milímetros, conforme granulometria. Em outras regiões do país essa mesma brita é comprada com a descrição de brita número dois. Se esta brita for pesquisada em Recife como brita número dois, poucos terão esse conceito e entendimento, podendo em muitos casos gerar informações incoerentes para os dados das pesquisas e seus resultados. Então, para os itens pesquisados numa pesquisa desse tipo, cabe ao pesquisador ser coerente, minucioso e detalhista, pois qualquer ausência ou mal-entendido da descrição do produto poderá acarretar problemas diversos.

\subsubsection{Tipo de preço}

O tipo de preço deve ser observado com bastante atenção. Preço varejo a vista, preço atacado, preço com frete e preço com incidências de impostos nacionais e federais são diferenciais de grande importância na análise final de um índice. Cada tipo de preço tem um objetivo especifico para ser coletado e, ignorar essa informação é literalmente mudar o foco da pesquisa a qual está sendo direcionada.

\subsubsection{As incidências nos preços}

Os impostos e incidências nos preços é algo que requer muita atenção e algum conhecimento tributário por parte do pesquisador. ICMS - Imposto sobre Circulação de Mercadorias e prestação de Serviços, IPI - Imposto sobre produtos industrializados, FRETE, PIS - Programa de Integração Social, COFINS - Contribuição para o
Financiamento da Seguridade Social, são apenas algumas incidências que dão configurações diferentes e expressivas nos preços, podendo torna-los completamente diferente do que a necessidade da pesquisa está precisando. Há produtos com muitas incidências nos preços. Saber se o preço coletado já está incluso ou não tais incidências é fundamental para a formulação dos índices. As bebidas alcoólicas por exemplo, tem em sua maior composição de preço, os impostos.

\subsection{8 Índices de Pesquisas}

As informações coletadas nas diversas pesquisas, em sua grande maioria serão transformadas em índices. São estes índices que norteiam as tendências e comportamentos. Os índices apresentam uma variedade de particularidades, objetivos e direcionamentos. Os índices buscam atender um expectativa e formular um conceito de um determinado parâmetro estudado. Devido a esta complexidade, cada processo e método usado na coleta, processamento e divulgação na formação de um índice são devidamente monitorados e estudados com base na mais apurada capacitação profissional e instrumentos tecnológicos.

A ênfase nos processos, entretanto, exige um enfoque mais acentuado na maneira como a atividade é realizada na organização, em contraste com a visão relacionada ao produto ou serviço em si, que se centra no que é o produto ou serviço.[40]

\subsection{9 Índice de Preço ao Consumidor}

Dentre os vários índices gerados pelos Institutos de pesquisas no Brasil, o Índice de Preços ao Consumidor (IPC) tem sido um índice de referência para avaliação do poder de compra do consumidor, conforme Figura 6, e este mede a variação de preços de um conjunto fixo de bens e serviços componentes de despesas habituais de famílias com nível de renda situado entre 1 e 33 salários mínimos mensais. Sua pesquisa de preços se desenvolve diariamente, cobrindo sete das principais capitais do país: São Paulo, Rio de Janeiro, Belo Horizonte, Salvador, Recife, Porto Alegre e Brasília. A pesquisa engloba as seguintes classes de despesas: Alimentação, Habitação, Vestuário, Saúde e Cuidados Pessoais, Educação, Leitura e Recreação, Transportes, Despesas Diversas e Comunicação.

\subsubsection{As Pesquisas e o Foco}

O propósito e objetivos das pesquisas são diversos. Porém, sempre as abordagens estão direcionadas a atender as necessidades econômicas do País. As metas estão direcionadas a atender sobretudo as diversas necessidades nacionais. Os Institutos de Pesquisas procuram atender essas necessidades e, muitos realizam pesquisas exclusivas e outros, com ampla variedade e metodologias. A motivação de uma pesquisa pode ser a problemática de se 
preencher uma lacuna nos conhecimentos. Satisfazer o cliente é o papel dos órgãos que geram e divulgam informações. Satisfação é o sentimento de prazer ou decepção que é resultado da comparação do que foi recebido com as expectativas da pessoa.[37] Os pesquisadores orientam a observação e o questionamento dos fenômenos sociais contribuindo para os conceitos e questões analíticas. Sendo assim, o economista não tenta pesar o valor real dos sentimentos humanos, e ele o avalia por seus efeitos que são muito mais concretos.[34]

\subsubsection{O Pesquisador e o Pesquisado}

Pode-se afirmar que nos processos de pesquisas existe uma verdadeira parceria entre pesquisador e pesquisado. Ambos precisam entender os propósitos por meio de uma clara e objetiva comunicação. A comunicação eficaz aliado ao senso de percepção aguçado pode viabilizar e facilitar o processo de coleta de dados. A comunicação, a percepção e a motivação são instrumentos que permitem desenvolver qualidades individuais e coletivas.[17] Ter habilidades apropriadas torna-se instrumento fundamental para o melhor desempenho e objetivos. Uma pessoa precisa de habilidades relacionadas à disciplina. Habilidades podem acrescentar algo a mais na análise de entendimento do desenvolvimento de um indivíduo e organização. $\mathrm{O}$ comportamento humano nas organizações também se resume na realização da pessoa em compreender as outras pessoas, e de desenvolver capacidades exclusivas, e é dessa forma que se destaca o autoconhecimento e a auto percepção. A gestão dos recursos humanos e organizacionais é um meio de entender e estabelecer parâmetros para empresas bem sucedidas. Os aspectos comportamentais humanos e organizacionais serão apresentados e abordados através do entendimento das relações de comunicação, percepção e motivação para o melhor desempenho.

\subsubsection{A liderança, as Pesquisas e os Resultados}

Todos os profissionais envolvidos em pesquisas estão cada vez mais esclarecidos de seu papel como instrumento direto na formação do conhecimento e divulgação da informação. O pesquisador, o economista e toda a liderança organizacional são treinados e orientados na busca para atender as expectativas. O professor Julio Lobos (1976), da Universidade Federal de Minas Gerais explica que o simples "bom senso" profissional não é suficiente para legitimar certas decisões organizacionais. Sendo assim, é possível perceber a ocorrência de avanços teóricos em termos de administração de pessoas, mas não há a incorporação direta destes avanços em muitas áreas. Administrar o comportamento das pessoas nas organizações por meio da formulação de objetivos que explicitem ações contextualizadas - especificando as situações nas quais as ações irão ocorrer e o modo como devem ocorrer, bem como os resultados desejados a partir delas parece ser uma forma alternativa de discutir modos de gestão, entendimentos comportamentais e desempenho.[4]

\subsubsection{Comunicação e Motivação nas Pesquisas}

Em pesquisas não é diferente. A motivação no ambiente de trabalho atrelado a uma comunicação eficiente promove melhores resultados. Um fator muito presente aos meios de pesquisa está as influências internas e externas do meio. Segundo Nassar e Figueiredo (2007, p. 20) a comunicação organizacional é um verdadeira frentes de batalhas.[39] Frente de batalha ecológica, a frente de batalha para manter e conquistar novos consumidores, a frente de batalha da comunicação interna e a frente de batalha das relações da empresa com governos e políticos. Sendo assim, manter-se imparcial é objeto de qualidade em pesquisas sobretudo na área de economia. Não ceder as questões particulares e politicas torna-se uma necessidade para uma informação consciente e transparente. Em relação a motivação profissional, um trabalhador que domina suas habilidades profissionais pode ser um ponto a mais na motivação e desempenho organizacional e investir em qualificação profissional é uma forma de garantir desempenho e competitividade. Pois, segundo a Teoria da necessidade de McClelland, um individuo pode ser treinado a aumentar sua motivação, e que essa motivação para a realização de uma tarefa especifica está relacionada com o desempenho. Muitas competências comportamentais são valorizadas no ambiente empresarial. Habilidades de liderança; automotivação, para o trabalho em equipe, criatividade destacam-se entre os diferenciais que as empresas buscam encontrar em seus colaboradores, entretanto, a excelência na comunicação interpessoal é item fundamental para o sucesso de líderes, colaboradores e equipes.[40] 


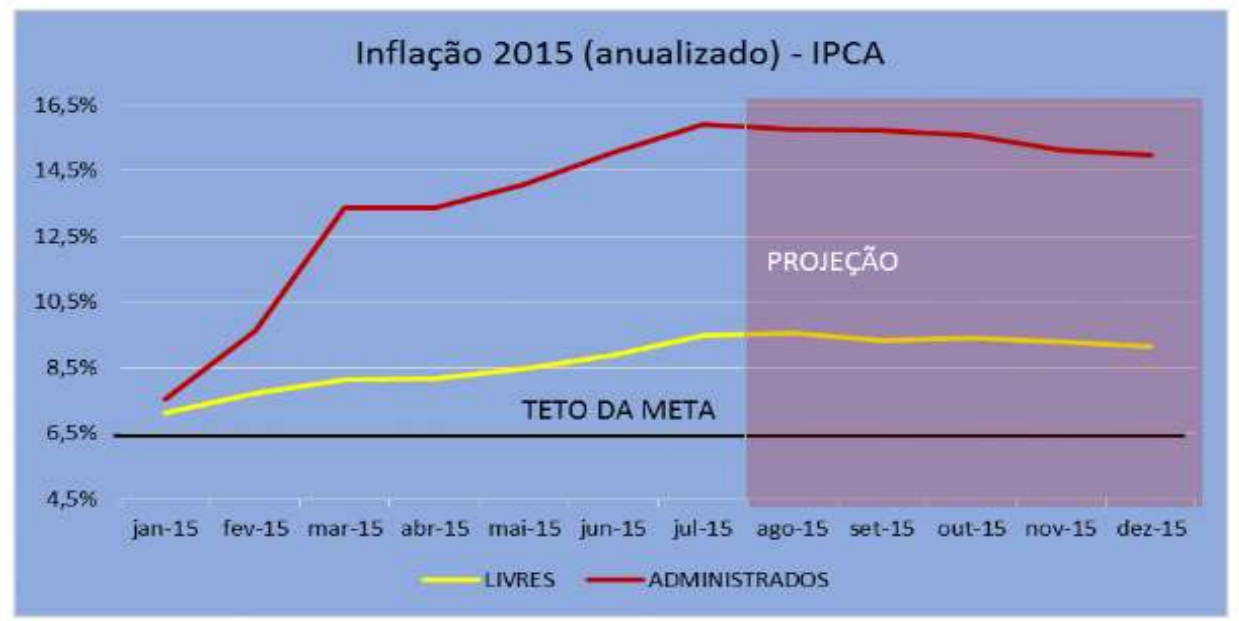

Fonte: Banco Central do Brasil e ITAÚ BBA; Elaboração própria

Figura 6: Gráficos são gerados e divulgados nas mídias

\section{Conclusões}

O objetivo deste trabalho foi investigar as variáveis que influenciam diretamente na qualidade de pesquisas, sobretudo na área de economia, utilizando como fonte de embasamento uma empresa do ramo de pesquisas em economia no estado de Pernambuco. Observou-se durante esse estudo que, a qualidade das informações geradas de pesquisas na área de economia, pode sofrer inúmeras influencias internas e externas, que em grande parte aparecem quase que imediatamente no ato da coleta. Que, alguns fatores influenciadores que possam ser entendidos como de menor grau de interferência, tais como a mobilidade nos grandes centros urbanos e o senso de percepção do pesquisador, estes também tornam-se parte de uma problemática cada vez maior na garantia e controle da qualidade das informações coletadas e geradas. Conforme delineado, conclui-se que, a garantia e o controle da qualidade em pesquisas econômicas precisam impreterivelmente de padronização das inúmeras atividades e, uma efetiva implantação de um modelo gerencial para a melhoria continua, tornando-se imprescindível o envolvimento do pesquisador e pesquisado numa comunicação assertiva e percepção social. Nota-se ainda que, o fator humano tem peso consistente e significativo e, muito suscetível a erros e interferências, e que pesquisadores motivados e treinados, com visão sistêmica para o Sistema de Gestão da Qualidade poderão promover um maior comprometimento das partes envolvidas no processo.

A ética, o comportamento organizacional e o panorama socioeconômico pode conduzir meios que se não devidamente identificados e monitorados, interferirão nos resultados finais de uma pesquisa, levando a erros graves. O senso de percepção de um pesquisador é visto como fator preponderante para mensuração das informações desejadas e analise das questões sociais inerentes ao meio estudado.

As ferramentas da qualidade devidamente implementadas tornam-se instrumento para mensurar e acompanhar os processos desde uma pesquisa pela internet, por telefone ou presencial, até sua divulgação nos meios de comunicação e aplicabilidade nas empresas. O pesquisador, o pesquisado e a liderança são todos suscetíveis aos fatores influenciadores da qualidade, e devem entender como objetivo principal da qualidade total, que a satisfação e a melhoria da qualidade de vida dos clientes internos e externos nas organizações é o foco final de toda e qualquer pesquisa. A avaliação durante todo o processo é de vital importância para mensurar o quanto se avança em direção às metas e corrigir possíveis desvios que venham a atrapalhar e/ou impedir o alcance das mesmas. Sendo assim, resumidamente conclui-se que é necessário:

- Maior autonomia do pesquisador no ato de coleta de informações de pesquisas: promover treinamentos regulares dos funcionários para tomada de decisão;

- Investimento na área de gestão de pessoas: promover visão sistêmica e identificar as necessidades de cada pesquisador;

- Promover material e equipamentos de fácil manuseio e acesso, contribuindo para maior agilidade nos prazos das pesquisas;

- Manter controle de segurança sempre ativo: manutenção de equipamentos;

- Oferecer subsídios de incentivos as pessoas e organizações que participam efetivamente das pesquisas. 


\section{Referências}

[1] KUNSCH, M. M. K. Planejamento e gestão estratégica de relações públicas nas organizações contemporâneas. In: Analisis, n. 34, 2006, p. 125-139. Disponível em: http://ddd.uab.cat/pub/ analisi/ 02112175n34p125.pdf Acesso em: 02 fev. 2016.

[2] ASSOCIAÇÃO BRASILEIRA DE NORMAS TÉCNICAS - ABNT. ABNT/CB-25 - gestão da qualidade e garantia de qualidade - terminologia NBR ISO 9001. Rio de Janeiro, 2008, 15p.

[3] M. M.. ISO série 9000 (versão 2000) - Manual de Implementação. Rio de Janeiro: Qualitymark, 2005.

[4] Percepção da qualidade da informação - Ronaldo Ronan. Brasília, v.35, n1, p.57-62, jan2006.

[5] B. C. F. L e R.J.M. Conversas com Economistas Brasileiros 1. São Paulo, Ed. 34, 1996.

[6] C. Antônio Lázaro; D. Gislene Regina. Qualidade. In: FACULDADES BOM JESUS. Gestão empresarial. Curitiba: Gazeta do Povo, 2002, p. 52.

[7] C. Antônio Lázaro; D. Gislene Regina. Qualidade. In: MENDES, Judas Tadeu Grassi. Gestão empresarial. Curitiba: Editora Gazeta do Povo, 2002.

[8] http://www.cin.ufpe.br/ if717/Pmbok2000/pmbok_ v2p/wsp_8.2.html. Acesso em: 02 fev. 2016.

[9] D. Pedro. Pesquisa e Construção de conhecimento: metodologia científica no caminho de Habernas. Rio de Janeiro: Tempo Brasileiro, 2000, p. 125.

[10] L. Sergio Vasconcelos de. Planejamento de Pesquisa: uma introdução. São Paulo: EDUC, 2000, p. 108.

[11] C. Antônio. Pesquisa qualitativa em ciências humana e sociais, Rio de Janeiro, ed. Vozes, 2011.

[12] G. Etienne. Manual de ergonomia: adaptando o trabalho ao homem. 4. ed. Porto Alegre: Bookman, 1998.

[13] DEMING, W. E. , Qualidade: a revolução da administração. Ed Marques Saraiva, 1990.

[14] ISHIKAWA, K. Controle de qualidade total: a maneira japonesa. Rio de Janeiro: Campus, 1997.

[15] A. Cristian. DIONNE Jean. A construção do saber. Manual de metodologia da pesquisa em ciências humanas. Ed. UFMG, 2007

[16] C. Idalberto. Administração: teoria, processo e pratica. 4. ed. Rio de Janeiro: Elsevier, 2007. V. 1. C. Idalberto. Gestão de Pessoas. 2. ed. Rio de Janeiro: Campus, 2004.
[17] W. III, John A.; H. John R. Comportamento organizacional: criando vantagem competitiva. 3. ed. São Paulo: Saraiva, 2012.

[18] M. Edmilson José Tonelli. Organização, sistemas\& métodos. Campinas: Editora Alínea, 2001.

[19] G. Ricky W.; M. Gregory. Fundamento do Comportamento Organizacional. São Paulo: Ática, 2006.

[20] D. Keith; N. John W. Comportamento humano no trabalho: uma abordagem organizacional. 2. Ed. São Paulo: Pioneira, 1996.

[21] R. Rui Martinho. Pesquisa Acadêmica Como Facilitar o Processo de Preparação de suas etapas, ed. Atlas, 2007.

[22] P. Roseli Aparecida Fígaro. Comunicação, mundo do trabalho e subjetividade. Revista de Economia Política das Tecnologias da Informação e Comunicação. v. 3, n. 3, set.-dez./2001.

[23] T. Maria Luísa Mendes. Valores humanos \& gestão: novas perspectivas. São Paulo: SENAC, 2009.

[24] T. Don. Economia digital: promessae perigo na era da inteligência em rede. São Paulo, ed. Makron Books, 1997.

[25] Q. Dante; T. Rosi Mary. Comportamento Organizacional. Fae, 2003. Disponível em: http://sottili.xpg.uol.com.br/publicacoes/pdf/ cap_humano/1.pdf. Acesso em: 11 mai. 2016.

[26] S. Peter. A quinta disciplina: caderno de campo: estratégias e ferramentas para construir uma organização que aprende. Rio de Janeiro: Qualitymark Ed., 2000, p. 592.

[27] M. Gabriel Sperandio; B. Juliana; D. T. Deonir. A qualidade percebida dos serviços prestados por uma agência de comunicação e satisfação do cliente: um estudo exploratório. Revista Brasileira de Gestão de Negócios. São Paulo, v. 10, n. 26, p. 17-26, jan./mar. 2008.

[28] C. Henrique Luiz; C. Mauro. Gestão de serviços: lucratividade por meio de operações e de satisfação dos clientes. São Paulo: Atlas, 2002.

[29] A. David A; K. V; D. George S., Pesquisa de marketing. Trad. Reynaldo Cavalheiro Marcondes. 2 ed. São Paulo: Atlas, 2004.

[30] (artigo) Estudo dos aspectos comportamentais de vendedores de material de construção e sua relação com a comunicação, percepção e motivação nos resultados. Marcio Oliveira Maia. Set2013.

[31] http://economia.ig.com.br/financas/meubolso/asdonas-de-casa-que-sao-experts-eminflacao/n123 7972481045.html. Acesso em 11 mai. 2016. 
[32] A. Fernanda Nayara da Silva. A comunicação no processo de gestão pela qualidade total no setor público: um estudo de caso do tribunal de Justiça do Estado de Minas Gerais. In: Intercom, 2009, Curitiba. Anais eletrônicos... Curitiba. 2009. Disponível em: http://www.intercom.org.br/papers / regionais/sudeste2009/expocom/EX14-0869-1.pdf>. Acesso em: 11 mai. 2016.

[33] G. Bradley T. Gerenciando o valor do cliente: criando qualidade e serviços que os clientes podem ver. São Paulo: Pioneira, 1996.

[34] G. Antônio Carlos. Técnicas de pesquisa em economia e elaboração de monografia. 4. ed. São Paulo, ed. Atlas, 2002.

[35] http://www.jornalopcao.com.br/reportagens/2015sera-o-ano-dos-reajustes-para-economia-brasileiraentenda-o-porque-7027/. Acesso em 21 mai. 2016.

[36] M. Edmilson José Tonelli. Organização, sistemas\& métodos. Campinas: Editora Alínea, 2001.

[37] K. Philip. Administração de marketing: análise, planejamento, implementação e controle. 5. ed. São Paulo: Atlas, 1998.

[38] L. Júlio. Administração de pessoal: prática versus teoria. Rev. adm. empres., São Paulo, v. 16, n. 4, Aug. 1976. Disponível em: <http://www. scielo.br/scielo.php?script=sci_arttext\&pid =S0034$75901976000400003 \& \operatorname{lng}=e n \& \mathrm{nrm}=\mathrm{iso}>$. Acesso em: 23 mai. 2016.

[39] N. Paulo; F. Rubens. O que é comunicação empresarial. São Paulo: Brasiliense, 2007.

[40] K.. Angelo; K. Robert. Comportamento Organizacional. São Paulo: McGcraw-Hill, 2006. 